\title{
O PROBLEMA DAS FIGURAS DA TRADUÇÃO
}

\section{Jerzy Brzozowski*}

RESUMO: Num artigo a ser lançado em breve - O problema das estratégias da tradução -, o autor elaborou um modelo tripartite, cujo topo ocupam os "fatores das escolhas estratégicas", conscientes e inconscientes. Como resultado da interferência desses fatores, obtemos combinações - sempre variáveis segundo as características do determinado texto - que podemos chamar, no caso da dominação de fatores conscientes, de "estratégias" e, no caso inverso, de "falta de pensamento estratégico".

A presença mais ou menos acentuada do pensamento estratégico é capital para as definições a seguir, e nomeadamente a das figuras da tradução. $\mathrm{O}$ autor do presente artigo sustenta que a visada estratégica (ou a falta da mesma) ajuda-nos a distinguir as figuras da tradução e o que podemos chamar, meramente, de erros.

A idéia chave deste texto é, pois, que qualquer tipo de modificação (shift) da mensagem não deve ser considerado uma figura de tradução. O uso dessa noção, para o autor, é justificado somente nos casos em que somos capazes de definir a natureza e as conseqüências da modificação; ou seja, o seu valor funcional. Nesse ponto, o autor discute o quadro elaborado por Andrew Chesterman no seu Memes of Translation, e pretende, a partir disso, propor uma nova classificação, baseada no conceito jakobsoniano das funções da linguagem.

* Universidade Jagelónica/Université Jagellonne, Cracovie. 
O resumo deste artigo diz: "qualquer tipo de modificação (shift) da mensagem não deve ser considerado uma figura de tradução. O uso dessa noção parece justificado somente nos casos em que somos capazes de definir a natureza e as conseqüências da modificação; ou seja, o seu valor funcional".

Sei que essa posição parece difícil de defender. À primeira vista, o que decide é o aspecto formal: uma metonímia ou metáfora, mesmo trivial, do tipo "ao pé da letra", não deixa de ser figura. Porém, as definições contidas nos bons dicionários não focalizam o aspecto formal. Eis a definição da Encyclopaedia Britannica:

Figure of speech: any intentional deviation from literal statement or common usage that emphasizes, clarifies, or embellishes both written and spoken language.

Essa definição acentua a intencionalidade e o valor funcional da figura que resolve algum problema de - digamos - insuficiência da linguagem comum. Seria um esclarecimento importante, porque, na teoria da tradução, a tendência dominante é a de considerar a figura de tradução como qualquer modificação $o^{1}$ do texto original (To) no texto alvo (Ta). Mas, nessa ótica, um erro, ou um acerto, que possuam as mesmas características formais de uma modificação, seriam chamados indiscriminadamente de figuras - o que acho inaceitável.

A diferença entre um erro e a figura da retórica às vezes é sutil: o solecismo, a zeugma, ou mesmo o pleonasmo são erros a menos que sejam usados intencionalmente. Portanto, vou insistir no sentido positivo da noção de figura de tradução; a defi-

1 Tal posição aparece, por exemplo, na obra muito apreciada L'horlogerie de Saint Jérôme (pp. 46, 51 e 74), de Marie-France Delport et JeanClaude Chevalier (1995). 
nição mais simples que gostaria de propor é a seguinte: trata-se de uma marca de criatividade do tradutor, com determinadas características formais e funcionais.

Do ponto de vista formal, a classificação bastante exaustiva de potenciais figuras de tradução foi elaborada por Andrew Chesterman no seu livro Memes of Translation. Um esclarecimento digressivo parece necessário: a sua lista, que vou apresentar em breve, foi chamada de "translation strategies". Mas, nesse ponto eu discordo de Chesterman. Ao contrário do que ele e outros teóricos eminentes defendem, considero que uma estratégia de tradução deve dizer respeito a uma visão geral de como se traduz o texto integral, portanto deve ser global e não local. Por outro lado, ela deve ser consciente.

O leitor encontrará os detalhes no meu artigo a ser publicado em breve na revista "Meta", Le problème des stratégies du traduire, onde elaborei um modelo, cujo topo é ocupado pelos "fatores das escolhas estratégicas", conscientes e inconscientes. Como resultado da interferência desses fatores, obtemos combinações - sempre variáveis segundo as características de determinado texto - a que podemos chamar, no caso da dominação de fatores conscientes, "estratégias" e, no caso inverso, "falta de pensamento estratégico". A prática demonstra que o segundo caso é mais freqüente, o que permitiu a Antoine Berman (1985) falar da "assistematicidade da escritura de tradução". Particularmente, prefiro evitar os dois extremos: não aceitando o uso abusivo do conceito de estratégia, mas apostando na criatividade do tradutor. Tal concepção, aliás, está em sintonia com a segunda e definitiva posição de Berman acerca do assunto, formulada no seu livro Pour une critique des traductions: John Donne (Berman, 1995).

As figuras não são, pois, qualquer modificação do texto de origem no texto de chegada; elas situam-se no nível local, o qual, por sua vez, se subordina ao nivel das estratégias. O contexto, a presença do pensamento estratégico decidirão, nos casos limites, se qualificamos uma modificação como figura ou meramente como erro. Examinemos o resumo do sistema proposto por Andrew Chesterman (Chesterman, 1997): 


\section{Syntactic strategies}

G1 Literal translation

G2 Loan, calque

G3 Transposition (VD) [any change of word-class, e.g. noun for verb, adjective for adverb]

G4 Unit shift [from Catford, 1965; e.g. one sentence for 2; word for phrase]

G5 Phrase structure change

G6 Clause structure change

G7 Sentence structure change

G8 Cohesion change

G9 Level shift [phonology, morphology, syntax and lexis]

G10 Scheme change [p.ex., figuras de construção: paralelismo, quiasmo, aliteração...]

2. Semantic strategies ["several of them derive from Vinay and Darbelnet's concept of modulation", comentário de A.Chesterman]

S1 Synonymy

S2 Antynomy

S3 Hyponymy

S4 Converses [the same state of affairs from opposing viewpoints]

S5 Abstraction change [from abstract to more concrete or from concrete to $\mathrm{m}$. a.]

S6 Distribution change [expansion or compression]

S7 Emphasis change

S8 Paraphrase ["semantic components at the lexeme level tend to be disregarded, in favor of the pragmatic sense of some higher unit such as a whole clause"]

S9 Trope change (cf. G10)

1. $\mathrm{ST}$ trope $=\mathrm{TT}$ trope

2. TT trope is of the same type, but not semantically identical

3. TT trope is of the same type, but not related lexically to the ST one (the source of the image is different)

4. ST trope $X=T T$ trope $Y$ [the general principle of figurativeness retained, but the realization of this feature is different

5. ST trope $X=$ TT trope $\varnothing$ 
6. ST trope $\varnothing=$ TT trope $\mathrm{X}$

$\mathrm{S} 10$ other semantic changes ["other modulations of various kinds" e.g. "change from oral to visual sense" or "attention from 'here' to 'there' = attention from 'there' to 'here']

\section{Pragmatic strategies}

Pr 1. Cultural filtering

Pr 2. Explicitness change

Pr 3 Information change

$\operatorname{Pr} 4$ Interpersonal change [the formality level, degree of emotiveness, etc.]

$\operatorname{Pr} 5$ Illocutionary change

Pr 6 Coherence change

$\operatorname{Pr} 7$ Partial translation [existe outra? J.B.]

Pr 8 Visibility change [trata-se do próprio autor ou do tradutor]

Pr 9 Transediting [correcções do original obviamente mal escrito]

Pr 10 Other pragmatic changes

Do ponto de vista das características formais, esse quadro parece-me um excelente ponto de partida para uma discussão aprofundada. Vou começar pelo fato de que as modificações decorrentes dessas "estratégias" são, na maior parte, locais, sendo que as demais podem ser tanto globais como locais. Portanto, o conceito de "figuras", em vez de "estratégias", pareceria mais adequado. Ainda assim, algumas delas não deixam de surpreender quanto à sua classificação nas categorias de ordem superior. Por que razão a tradução literal, o empréstimo ou o calco pertenceriam à categoria "sintática"? Ousaria dizer: por falta de um critério melhor que, na verdade, o quadro apresentado não oferece. Poderíamos prosseguir: na verdade, a maior parte das estratégias ou figuras "sintáticas" nada diz sobre o efeito de tal ou qual modificação, registrando-se apenas o ocorrido. Do ponto de vista da qualidade da comunicação, essas informações são simplesmente irrelevantes; aliás essa constatação, justamente, foi o impulso decisivo para eu procurar um outro quadro de classificação das tais figuras (estratégias) de tradução. 
A primeira pista para esse intento foi-me dada pelo próprio Andrew Chesterman. Em sua publicação recente (Chesterman, 2004) sobre os chamados "universais" da tradução, ele distingue entre os "S-universals" (que dizem respeito às modificações que sofre a mensagem original na tradução) e os "T-universals" (o impacto do processo de tradução sobre a mensagem na língua de chegada). Nesse ponto Chesterman é mais que convincente e, portanto, pensando nas figuras da tradução, acho que se deve adotar, sem restrições, a divisão proposta. As figuras têm tradicionalmente a seguinte característica: contrastam com o modo de falar "neutro", ou "comum". Ora, em se tratando das figuras de tradução, podemos nos perguntar: tais figuras contrastam com as estruturas de que língua? A de origem ou a de chegada? Entre as figuras do quadro acima, algumas não modificam em nada o original. Portanto, permito-me a primeira divisão:

as Fo (figuras de texto original) e as $\mathbf{F a}$ (figuras do texto alvo).

As Fa (figuras do texto alvo) seriam as seguintes:

1. Tradução literal - na medida em que ela modifica os costumes lingüísticos e/ou estilísticos da língua de chegada

2. Empréstimo

3. Calco

4. Neologismo (inspirado pelo texto original a traduzir)

Porém, não abordamos ainda o problema do valor funcional de eventuais figuras. O critério da classificação de Chesterman é semiológico; em seu modelo, as três categorias principais são justamente os ramos principais da semiótica. Mas... figura não é conceito pertencente à semiótica; ela pertence à retórica. E dentro desse último campo, a definição das figuras de linguagem é a seguinte:

(...) São formas de expressão mais localizadas em comparação às funções de linguagem, que são características globais do texto. (Wikipédia, versão portuguesa) 
Ora, considero que as figuras da tradução também podem - e devem - ser consideradas como "mais localizadas em comparação às funções de linguagem", e esse é o princípio da classificação que me permito abaixo propor. Antes de fazê-lo, uma última observação. No caso de figuras de retórica, existem vários critérios pertinentes, que decorrem de vários domínios, segundo os quais podemos defini-las. Esses critérios completam-se e cooperam entre si, mas não se anulam. Portanto, no meu quadro, conforme se disse acima, inspirado parcialmente no trabalho de Chesterman, aparece um acréscimo na classificação, baseado na distinção de Quintiliano ${ }^{2}$. Essa adaptação moderna do modelo clássico é de autoria do ucraniano Koptilov (Koptilov, 1968), e os quatro tipos de transformação por ele propostos são os seguintes: amplificação, redução, inversão e substituição. Esses tipos aparecem como muito produtivos em todas as subdivisões do quadro que apresento abaixo, o das Figuras do texto original:

\section{Função referencial}

I.1 Modulação: em que se trata do mesmo estado de coisas, mas de um ponto de vista oposto. É uma das propostas do trabalho clássico de Vinay e Darbelnet (1978). Chesterman propõe, entre as suas figuras derivadas, a antinomia ou "converses". Mas seria necessária essa distinção? Nesta etapa prefiro utilizar a denominação mais geral de modulação. Eis um exemplo:

- "Ah! Que plutôt du ciel la flamme me dévore!" [Racine, Phèdre, Oenone, v. 881]

- "Senão, que do inferno me queime o fogo!"3

2 Quintiliano distingue: figurae per adiectionem, per detractionem, per transmutationem, per immutationem.

3 Quase todos os exemplos de figura foram tirados das traduções existentes; contudo, quando os exemplos são em português e o nome do tradutor não aparece, trata-se de adaptações minhas de traduções polonesas.

TradTerm, 14, 2008, p. 157-176 
O exemplo acima incorre em certo risco: o sentido geral dessa frase focaliza a punição do perjúrio possível. Porém, a figura utilizada na tradução traz um deslize incrivel: entre uma aceitação da punição, que vai até a perda de vida, e a aceitação da danação, para uma pessoa crente, a diferença é enorme! Poderíamos aqui falar, conjuntamente à modulação, de uma amplificação (indevida!) da função referencial.

\section{I.2 Sinonimia}

- Les superbes remparts que Minerve a bâtis [Racine, Phèdre, Oenone, v. 360]

- $[\ldots]$ que Atena construiu

I.3 Generalização: o objeto mencionado não existe, ou é pouco conhecido na cultura de chegada, mas existe o seu hiperônimo ou equivalente funcional:

truffe - cogumelo; wojewoda - préfet - governador

O segundo exemplo (governador) foi encontrado na imprensa brasileira e francesa, tratando-se da suprema autoridade regional na Polônia. Contudo, além dessa característica geral, os detalhes importantes (tais como as competências, a dependência ou não do governo central, etc.) diferem muito para cada um desses altos funcionários.

I.4 Explicitação: quando o nosso leitor projetado - aqui, um francês "descristianizado" - não dispõe de competência conotativa suficiente:

- Eso del centurión le parecía al monaguillo más bien cosa de Semana Santa y de los pasos de la oración del huerto [R. Sender, Réquiem por un campesiono español] ${ }^{4}$

- Le centurion, pour l'enfant de choeur, c'était plutôt une histoire de Semaine Sainte, des pasos de la prière au jardin des Oliviers.

4 Apud Jean-Claude Chevalier, Marie-France Delport, op. cit., p. 48. 
I.5 Filtragem cultural: quando um elemento mais prototípico na cultura de chegada $(\mathrm{Cc})$ foi escolhido para substituir um outro, prototípico na cultura de origem, mas periférico, ou ausente na Cc. A definição, no âmbito da lingüística cognitiva, é nova, mas o mecanismo é bem conhecido; trata-se da equivalência, no entender de Vinay e Darbelnet:

- to carry coals to Newcastle

- porter de l'eau à la rivière

O conceito de filtragem cultural, de Juliane House, foi aqui comentado em termos da linguística cognitiva. Tanto o comentário como o exemplo são de autoria de Bernd Stefanink e Ioana Balacescu ${ }^{5}$.

I.6 Amplificação (acréscimo): acrescentamos uma informação suplementar sobre o estado de coisas que julgamos útil para o nosso leitor projetado; aqui, um turista apressado:

- Porte de Paris: [...] Arc de Triomphe symbolisant le rattachement de Lille au Royaume de France [folheto turístico Le tour de Lille en 1 heure]

- [...] this triumphal arch in honour of Louis XIV commemorates the return of Lille to the kingdom of France

I.7 Substituição: uma opção possível no campo semântico, que se aproveita de um outro atributo do mesmo objeto - p. ex., raio por trovão - ou usa um outro objeto do mesmo campo semântico para falar de um sentimento compartilhado entre ambos:

- Ton souvenir luit en moi comme un ostensoir [Baudelaire, Harmonie du soir]

- Tua lembrança arde em mim como uma vela benta

5 Bernd Stefanink, Ioana Balacescu. Traduction et créativité, "Le français dans le monde". Mars-Avril 2002 - N³20, versão eletrônica on-line, p. 3. 
I.8 Inversão: muda um atributo essencial ou uma função básica. P. ex.: agente/paciente:

- O Satan, ton Temple [Baudelaire, Les litanies de Satan]

- Oh! Satanás, Teu templo

Nesse caso, o uso da maiúscula do original acentua a relação institucional (a Igreja) entre o "eu" do poema e o que representa Satanás. Na tradução, em vez disso, rejeita-se a relação institucional para acentuar uma privilegiada relação individual do narrador com o Anjo caído. Na verdade, o tradutor não concorda ideologicamente com o autor: é um exemplo de tradução polêmica.

I.9 Redução: censura, atenuação, eufemismo? A não confundir com a omissão:

- NATO must make putting an end to the hostilities its number one priority over the next few months - at whatever cost. ${ }^{6}$

- Contribuer à l'arrêt des hostilités en Yougoslavie en utilisant tous les moyens possibles, l'OTAN en particulier, devrait être le devoir numéro un de l'Europe dans les prochains mois

\section{Função apelativa ou impressiva}

Chesterman fala, entre as figuras pragmáticas, do Interpersonal change, que significa a mudança "do nivel de formalidade, o grau de emotividade e de engajamento pessoal, o nível de tecnicidade do léxico, etc.: tudo que envolve a mudança de relacionamento entre o autor do texto e o leitor" (Chesterman, 1997:110, tradução nossa). E fácil perceber que o "nível de formalidade", "o engajamento pessoal” e especialmente aquele indefinido "tudo o que envolve a mudança de relacionamento entre

6 Apud: Lance Hewson, Images du lecteur, "Palimpsestes", n 9, 1995. 
o autor e o leitor" diz respeito às emoções ou comportamentos esperados da parte do interlocutor. O primeiro item seria, aqui, a amplificação.

\section{II.1. Amplificação}

- Do it now.

- Faça-o imediatamente. [não há figura]

- Faça-o a g o r a !

Trata-se de um exemplo modelo da função apelativa, e o efeito de amplificação foi obtido pelos meios clássicos que estimulam um maior "engajamento pessoal". No exemplo seguinte, isso já não é tão evidente. O título de um romance tem, dentre outras funções, de chamar a atenção de um leitor potencial. No caso do Cascalho, de Herberto Sales, um leitor européu dos anos 1980, especialmente no chamado leste européu (países vivendo sob a dominação soviética) dificilmente deixar-se-ia seduzir por esse termo técnico, de conotações desconhecidas. Portanto, o editor polonês propôs um título capaz de estimular a imaginação de um leitor ávido de exotismo:

- Cascalho

- Diamantes de Andarai ${ }^{7}$

\section{II.2 Redução}

O exemplo precedente foi tirado de uma publicação dos anos 1980, e o horizonte das expectativas do leitor virtual daquele tempo (um polonês vivendo no regime comunista, sonhando com a liberdade e as viagens impossiveis por falta de dinheiro e do... passaporte) parece bem diferente do horizonte do leitor de hoje. $\mathrm{Na}$ época da televisão por satélite, da internet e das viagens fáceis, o exotismo já não é coisa tão rara, até cansa, às

7 Herberto Sales. Diamenty z Andarai. Wydawnictwo Literackie, Kraków, 1982 . 
vezes parece um pouco kitsch. Talvez seja esse o motivo que convenceu o tradutor do filme de Zhang Yimou, um chinês de Hong-Kong, a propor um título mais sóbrio:

- Curse of the golden flower

- A Imperatriz ${ }^{8}$

\section{II.3 Adaptação aos "cultural scripts"}

O conceito dos "cultural scripts", descrito de maneira esclarecedora nos trabalhos de Anna Wierzbicka ${ }^{9}$, refere-se aos comportamentos lingüísticos típicos, ou convencionais numa dada cultura. A motivação (segundo o sentido que dá a esta palavra Chesterman, 1997) seria simples: o desejo de conformarse com as normas, no caso, as de boa educação. No Brasil, não há absolutamente nada de mal-educado em dizer ao empregado de mesa:

- Moço! Quero um cafezinho.

Contudo, traduzindo essa frase para o francês, admitindose que ela apareça, por exemplo, num romance, diremos provavelmente:

- Monsieur! Un café, s'il vous plaît.

Esse mecanismo parece também presente, em certo grau, nos itens seguintes, silence treshold e significance treshold.

8 Apud "Gazeta Wyborcza", 17.03.2007.

9 cf. Wierzbicka, A. (1994) 'Cultural scripts': a new approach to the study of cross-cultural communiction. In: Putz, M. (ed.) Language contact and language conflict, John Benjamins, Amsterdam \& Philadelphia. 


\section{Função fática}

Na cultura ocidental, a função fática pesa pouco no processo da comunicação, porém, dois fenômenos mencionados por Chesterman (1997:114) ao tratar do assunto merecem nossa atenção.

III.1 Silence treshold: ou seja, o "limite de tolerância do silêncio"; está ligado à impressão que experimentamos durante uma conversa - de que convém dizer alguma coisa em certo momento, pois guardar silêncio seria mal-educado, ou significaria algo que não queremos dar a entender. Esse limite é, em parte, determinado culturalmente, em outra parte depende da sensibilidade do próprio locutor. Esse aspecto pragmático oferece um pouco mais de consistência à "função fática" de Jakobson, a qual, na verdade, comparado às outras funções, me parecia sempre marginal. Ao lado do fenômeno de silence treshold, Chesterman fala do seu derivado, significance treshold; ou seja: não se trata apenas de reagir, mas da qualidade da nossa reação, que deve ser adequada às expectativas do nosso interlocutor. Essas expectativas são - e lá voltamos ao problema das figuras de tradução - culturalmente variáveis.

III.2 Significance treshold: ou reação típica/esperada do interlocutor. Nesse caso trata-se não apenas de quebrar o silêncio, mas da qualidade da nossa resposta. No exemplo seguinte, muito simples, essa qualidade aparece nos sinais de empatia, crescentes nas versões lingüísticas consecutivas:

- Oh yes... yes, indeed... yes... yes... [Fawlty Towers, Sybil ao telefone]

- Ah oui?... oui, je t'écoute... c'est affreux, ça... oui...

- É verdade? Nossa!... Não diga... Meu Deus!...

Entramos aqui deliberadamente no terreno de estereótipos lingüísticos, ligados às imagens das respectivas nações. A versão inglesa provém da minissérie satírica da BBC, na qual o 
autor de Monty Python auto-ironiza os costumes ingleses. A voz da Sibil, que ouve as queixas de sua amiga, é até repleta de empatia, mas o texto em si reflete a "fleuma britânica". Na versão francesa aparece um pouco mais de engajamento; contudo, é o mínimo que exige a boa educação. A última versão dá conta dos usos lingüísticos brasileiros: é uma reação típica de uma amiga, tal que se pode perceber nas famosas "novelas da Globo". Essas novelas, se não refletem exatamente a vida real, com certeza influenciam os comportamentos das pessoas: as reações exageradas dos protagonistas criam um novo padrão de comportamento lingüístico; conseqüentemente, uma pessoa que não reagisse da forma adequada, mostrando o grau de engajamento necessário, poderia arriscar a ser considerada mal-educada.

\section{Função emotiva}

Na classificação de Jakobson, a função emotiva constitui uma categoria à parte, muito importante, e acho sensato seguir aqui o velho clássico, aproveitando, contudo, as propostas de outros teóricos. A primeira delas vem do trabalho de Chesterman já citado aqui (Chesterman, 1997) e trata de "Emphasis change".

\section{IV.1 Emphasis change}

O último exemplo da categoria anterior (função fática, III.2) mostra também a mudança de carga emotiva contida no original e na tradução, mesmo que se trate de uma situação convencional. No que me permito chamar a "versão brasileira" dessa conversa, reflete-se a pressão do horizonte de expectativas do usuário de língua típico. Ora, na cultura do Brasil mostram-se, com naturalidade, mais emoções do que na cultura francesa, e muito mais que na cultura inglesa, famosa pela sua "frieza". Os pontos de suspensão sugerem, como noutras versões lingüísticas, que não se trata de notícias boas; a diferença aparece, aqui, nos pontos de exclamação, que sublinham o "calor humano" do co- 
municado. Não se trata, porém, de nada mais do que uma maneira convencional, culturalmente marcada, de falar; o nome adequado dessa figura parece-me emphasis change, conforme a proposta de Andrew Chesterman.

\section{IV.2 Redução}

A carga emotiva do texto de origem pode mudar de várias maneiras. A mais óbvia resulta do uso da pontuação. O exemplo seguinte utiliza a tradução portuguesa de um conto de Witold Gombrowicz:

- Statek jest dobry - odparł ufnie kapitan [...] - A choćby i nie był doskonały! - rzekł kapitan mierząc władczo dumnym spojrzeniem roztocz wód. - Choćby i nie był doskonały! Przypuśćmy, że jest gdzie szpara! [Bakakaj, p. 114-115]

- O barco é bom - respondeu-me, confiante, o lobo-do-mar [...] E mesmo que não fosse esplêndido... disse o comandante, examinando com olhar altivo a imensidade das águas - sim, mesmo que não fosse esplêndido... Suponhamos que houvesse uma fresta qualquer... Bakakai, p. 38 $]^{10}$

Sem dificuldade, mesmo não conhecendo o básico da língua polaca, percebemos que os três pontos de exclamação foram substituídos na tradução por três pontos de suspensão. O uso dos sinais de pontuação é de livre escolha do tradutor; o que me parece importante, contudo, é que, nesse caso, não se trata mais de obedecer a algum padrão cultural: Álvaro Cabral decidiu desta maneira que, na sua interpretação, o comandante é menos "confiante e altivo".

10 Witold Gombrowicz. Bakakai. Rio de Janeiro, Editora Expressão e Cultura, 1968 (trad. Álvaro Cabral). 


\section{IV.3 Amplificação}

- Des vêtements souillés, des blessures ouvertes,

Et l'appareil sanglant de la Destruction! [Baudelaire, La Destruction]

- Roupas manchadas de sujeira, feridas purulentas

$\mathrm{E}$ da selvagem destruição sangrenta ferramenta.

As amplificações são fáceis de perceber. Trata-se de dois adjetivos qualificativos e um adjunto adverbial, cuja função é reforçar a imagem - note-se, porém, que o ponto de exclamação, presente no original, desapareceu. O eminente tradutor polaco não quis "forçar a barra", já que em alguns versos antes ele colocou o ponto de exclamação num lugar onde o texto original continha apenas uma vírgula. Esse problema aparece no exemplo seguinte, bem mais complicado, onde a amplificação vem reforçada de inversão.

\section{III.4. Inversão}

- II me conduit ainsi, loin du regard de Dieu, [Baudelaire, La Destruction]

- E longe de mim estão os olhos de Deus!

O ponto de exclamação significa que, para o tradutor, o que acontece aqui é o mais importante, e não necessariamente as palavras reforçadas com o ponto de exclamação do original (cf. o exemplo anterior). Aparece, nesse caso, uma posição ideológica do tradutor, ligeiramente diferente da do autor: perder o contato com Deus é o ponto culminante, o resto não é tão dramático.

\section{Função poética}

Entre as figuras (estratégias) semânticas, Chesterman inclui a subcategoria trope change, a qual se subdivide como segue: 
1. $\mathrm{ST}$ trope $=$ TT trope

2. TT trope is of the same type, but not semantically identical

3. TT trope is of the same type, but not related lexically to the ST one (the source of the image is different)

4. ST trope $X=T T$ trope $Y$ [the general principle of figurativeness retained, but the realization of this feature is different]

5. ST trope $\mathrm{X}=$ TT trope $\varnothing$

6. ST trope $\varnothing=$ TT trope $X$

Podemos adotar esse conjunto de combinações propostas por Chesterman, com algumas restrições. A primeira é que, na minha classificação modificada, não há motivo para restringir os mecanismos acima expostos só aos tropos; antes, cabem aqui todas as figuras de retórica. Outra objeção: se quisermos manter rigorosamente a definição de figura de tradução, o item (1) não faz sentido aqui, incluído entre as "figuras do texto original": se não há qualquer modificação do texto original, não podemos falar da figura de tradução ${ }^{11}$. Do mesmo modo, não cabe aqui o item (5): a omissão mera e simples de uma figura do original não deve ser considerada como figura de tradução, mesmo se fosse consciente.

A tradução inglesa de Barbara Johnson da famosa Carta de Sollers a Jacques Derrida ("Lettre de Sollers"), da qual vou citar apenas um fragmento ${ }^{12}$, pode ilustrar praticamente todas as figuras acima mencionadas.

- $\quad$ MIMIQUE, ou plutôt mi+mi+que, c’est à dire deux fois les moitiés plus l’indication ou l’intimation subjonctive de la subordination mimée; mi-mais? mais-qui? mimi à que(ue)? queue de mémé?

11 Evidentemente, o impacto do mesmo tropo nas duas culturas pode, e deve, ser diferente; mas a análise desse fenômeno excede o quadro da presente classificação.

12 Para mais detalhes, cf. meu artigo Barbara Johnson traduit la "lettre de Sollers", "Synérgies Pologne”, 3/2006. 
Le si lance et défie le texte en excès comme ce qui succèdedans 1'après mi-dit-à la répétition du rire en écho mimé (rimé) l'arrivée d'or étant tout d'abord musique (or-chestre) et cela fait (si+or) =soir au milieu des rôles et du lustre qui mentsilence meurtrier, silence tué-

- MIMIQUE, or rather meme+meek, that is, mimed selfeffacement; mimicry-me, me cry? crime, me? my mere key? mama's queue?

The sigh lends and dares the text in excess as that which follows - in the after-no one - the repetition of l'after in a mimed (rhymed) echo the coming of the golden ore being at first music (or-chestra), the son or us, and then, amid the roles, the soul luxury of the lying lustre, the sigh node, the sign ode, the synodical stillness, the killed ode-

Barbara Johnson reproduz as aliterações do texto de Sollers (1); ela guarda a paronomásia "dans l'après mi-dit" - "in the afterno one", mas as palavras que constroem essas figuras não sugerem a mesma coisa (2); as metáforas "silence tué" e "killed ode" são obviamente do mesmo tipo, e até chegam a significar a mesma coisa, sem utilizar as mesmas palavras (3); a expressão "the soul luxury of the lying lustre" introduz uma figura ausente na expressão "du lustre qui ment" (6), porém, esse excesso é mais que justificado, por consistir numa alusão ao texto que inspirou a "Carta de Sollers"; e, obviamente, certas figuras do texto francês não foram reproduzidas (5) ou compensadas pelo uso de outro tipo de figura (4).

Vamos sublinhar, mais uma vez, que nem sempre os critérios propostos por Chesterman são suficientes. Os quatro tipos de transformação do texto traduzido (Koptilov) mostram-se produtivos também aqui. Quanto à redução, é possivel que a metáfora, inovadora e forte no original, resulte convencional na tradução (sem se levar em conta os fatores 1-3) ou, pelo contrário: uma figura convencional do original seja amplificada em termos da sua carga metafórica.

No texto examinado, temos ainda uma proliferação de substituições, que desempenham uma função poética importante, 
sem que a definição dessa figura mude: trata-se sempre de um outro atributo do mesmo objeto ou um outro objeto do mesmo campo semântico para falar do sentimento compartilhado entre ambos: "the killed ode" por "le silence tué" seria um bom exemplo da figura em questão. Porém, sendo que não mudam as características formais dessa figura, mesmo que sejamos capazes de expandir o seu valor funcional, seria justo incluir um novo item dentro da função poética? Essa questão me parece, por enquanto, em aberto.

Por outra parte, deve-se acrescentar que as funções de linguagem formam um conjunto, e coexistem/cooperam numa leitura holística de qualquer texto. Pode então acontecer que uma figura, suponhamos, dentro da função referencial ou impressiva, altere a função poética. Eis um exemplo esclarecedor que aparece num fragmento do poema de Wislawa Szymborska, Alguma gente (Jacyludzie), em traduções portuguesa e espanhola:

Sería útil alguna invisibilidad

Alguna parda petrificación

$\mathrm{Y}$ aún mejor fuera

\section{Una rabia}

Por un corto tiempo o largo ${ }^{14}$.
Daria jeito alguma invisibilidade,

Um dom de pedra parda, ou ainda melhor, de não ser, por certo tempo breve ou mesmo longo ${ }^{13}$.

O tradutor colombiano, sugerindo ao seu leitor a reação adequada, a de revolta, não confia na sua capacidade de perceber a ironia fina da autora. Ele procede a uma amplificação dentro da função impressiva (conativa, apelativa), mas a destruição da ironia leva à redução da função poética. Tal problema não aparece na tradução portuguesa.

Concluindo: não podemos perder de vista que as figuras de tradução (como também, aliás, as figuras de retórica) podem e devem ser definidas por vários critérios, e que esses são complementares. Para um efeito final concorrem, ao mesmo tempo, várias figuras e várias funções; ao tradutor compete analisar

\footnotetext{
13 W. Szymborska. Paisagem com grão de areia. Relógio d’Água, Lisboa, 1998 (trad. Júlio Sousa Gomes).

14 Tradução de B. Piotrowski (Colômbia).
} 
qual delas desempenha o papel primordial, sem perder de vista - na medida do possivel - todas as funções restantes.

\section{Bibliografia}

BERMAN, A. (1985) La traduction et la lettre ou l'auberge du lointain.

In: Tours de Babel, Trans-Europ-Repress.

BRZOZOWSKI J. (2001) Traces d'une présence. Miscellanea in honorem

Professoris Ursulae Dmbska-Prokop, Kraków, Wydawnictwo UJ.

BRZOZOWSKI, J. (2006) Barbara Johnson traduit la "lettre de Sollers", "Synérgies Pologne", 3/2006.

CHESTERMAN, A. (1997) Memes of translation. The spread of ideas in translation history. John Benjamins, Amsterdam/Philadelphia.

CHESTERMAN, A. (2004) Hypotheses about translation universals. In: HANSEN, G., MALMKJAER, K., GILE, D. (eds.) Claims, Changes and Challenges in Translation Studies. John Benjamins, Amsterdam/ Philadelphia Chevalier J.-C, Delport M.-F. (1995) L'horlogerie de Saint Jérôme, Paris, PUF.

HEWSON, L. (1995) Images du lecteur. "Palimpsestes", nº 9.

KOPTILOV, W. (1968) Transformacija chudozestwiennogo obrazu w poeticzeskom pieriewodie. In: Tieoria $i$ kritika pieriewoda. Moskva.

MESCHONNIC, H. (1973) Pour la poétique, II, Gallimard, Paris.

STEFANINK, B.; BALACESCU I. (2002) Traduction et créativité, "Le français dans le monde". Mars-avril 2002 - n 320.

VINAY, J.P.; DARBELNET J. (1978) Stylistique comparée du français et de l'anglais. Didier, Paris.

WIERZBICKA, A. (1994) 'Cultural scripts': a new approach to the study of cross-cultural communiction. In: M. PUTZ (ed.) Language contact and language conflict. John Benjamins, Amsterdam \& Philadelphia. 